\title{
Protective effect of a hydrogen sulfide donor on balloon injury-induced restenosis via the Nrf2/HIF-1 $\alpha$ signaling pathway
}

\author{
KEN LING $^{1 *}$, ANCONG XU $^{2 *}$, YUNFEI CHEN $^{3}$, XUEYIN CHEN $^{1},{\text { YIQING } \text { LI }^{3} \text { and WEICI WANG }}^{3}$ \\ ${ }^{1}$ Department of Anesthesia, Union Hospital, Tongji Medical College, Huazhong University of Science and Technology, \\ Wuhan, Hubei 430022; ${ }^{2}$ The Third Affiliated Hospital of Wenzhou Medical University, Wenzhou, Zhejiang 325200; \\ ${ }^{3}$ Department of Vascular Surgery, Union Hospital, Tongji Medical College, Huazhong University of \\ Science and Technology, Wuhan, Hubei 430022, P.R. China
}

Received April 27, 2018; Accepted January 10, 2019

DOI: $10.3892 / \mathrm{ijmm} .2019 .4076$

\begin{abstract}
Restenosis is liable to occur following treatment with endovascular interventional therapy. Increasing evidence indicates that hydrogen sulfide $\left(\mathrm{H}_{2} \mathrm{~S}\right)$ exhibits numerous physiological properties, including antioxidative and cardioprotective disease properties. Thus, the present study aimed to investigate the anti-restenosis effects of $\mathrm{H}_{2} \mathrm{~S}$ and its protective mechanisms. A balloon dilatation restenosis model was used, in which model Sprague-Dawley rats were treated with sodium hydrosulfide (NaHS: A donor of $\mathrm{H}_{2} \mathrm{~S}, 30 \mu \mathrm{mol} / \mathrm{kg}$ ) by intraperitoneal injection for 4 weeks. Histological observations of the carotid artery were performed, and $\mathrm{H}_{2} \mathrm{~S}$ production and the expression of Nuclear factor-E2-related factor 2 (Nrf2)/hypoxia-inducible factor (HIF)-1 $\alpha$ signaling pathway proteins were measured. In addition, human umbilical vein endothelial cells (HUVECs) were treated with NaHS following the inhibition of Nrf2 or HIF-1 $\alpha$ expression. The expression of Nrf2/HIF-1 $\alpha$ signaling pathway proteins, tube formation and cell migration were evaluated thereafter. The results demonstrated that NaHS treatment significantly increased $\mathrm{H}_{2} \mathrm{~S}$ production in rats with restenosis, and that neointimal thickness decreased significantly in arteries with restenosis. Furthermore, an increase in $\mathrm{H}_{2} \mathrm{~S}$ production enhanced the nuclear accumulation of Nrf2 and expression of its downstream targets, heme oxygenase-1 and superoxide dismutase, as well as HIF-1 $\alpha$. Similar effects of NaHS on the expression of these proteins were observed in HUVECs. Additionally, these findings indicated that
\end{abstract}

Correspondence to: Professor Yiqing Li and Dr Weici Wang, Department of Vascular surgery, Union Hospital, Tongji Medical College, Huazhong University of Science and Technology, 1277 Jiefang Road, Wuhan, Hubei 430022, P.R. China

E-mail: yiqingli2016@163.com

E-mail: weiciwang@gmail.com

${ }^{*}$ Contributed equally

Key words: hydrogen sulfide, restenosis, neointimal hyperplasia, nuclear factor-E2-related factor 2, hypoxia-inducible factor-1 $\alpha$
NaHS-induced HIF-1 $\alpha$ expression was dependent on Nrf2 expression. NaHS treatment also markedly increased tube formation by upregulating vascular endothelial growth factor expression and cell migration, both of which were mediated by the Nrf2/HIF-1 $\alpha$ signaling pathway, and suppressed the migration and proliferation of human vascular smooth muscle cells. Thus, NaHS-mediated $\mathrm{H}_{2} \mathrm{~S}$ production was observed to prevent neointimal hyperplasia, promote activation of the Nrf2/HIF-1 $\alpha$ signal pathway, and enhance HUVEC tube formation and migration, thereby exerting protective effects on balloon injury-induced restenosis.

\section{Introduction}

As percutaneous coronary intervention became widely adopted in the 1980s, restenosis was reported in 30-60\% of patients, most presenting with recurrent symptoms 1-4 months post-procedure $(1,2)$. In recent years, with the increasing prevalence of vascular stenosis, potential remedial strategies, including medical therapy, surgical bypass and endovascular revascularization, are becoming more widely applied in its clinical treatment $(3,4)$. Endovascular interventional therapy, including percutaneous transluminal angioplasty (PTA) and stent implantation, has demonstrated positive effects in the treatment of vascular stenosis $(5,6)$. However, the recurrence rate of restenosis, a major drawback of PTA, is as high as 19.7 and $60 \%$ within the first and fifth years following surgery, respectively $(7,8)$. Restenosis is a pathological outcome of excessive oxidative stress and repair responses in injured local blood vessels in response to interventional therapy (8), leading to a poor prognosis and inferior quality of life in patients with vascular stenosis. The post-operative occurrence of restenosis is one of the major challenges associated with endovascular intervention and represents a worldwide problem.

Vascular endothelial cell damage induced by PTA is an essential factor in the occurrence of restenosis (9). Furthermore, injured endothelia induce the production of reactive intermediates, including reactive nitrogen species and reactive oxygen species (ROS), leading to endothelial dysfunction (10). It has previously been demonstrated that the level of ROS in local blood vessels increases following PTA surgery or stent implantation (11-13). Upon injury, endothelial dysfunction promotes 
the excessive proliferation and migration of vascular smooth muscle cells (VSMCs) and triggers neointimal hyperplasia, resulting in narrowing of the lumen following endovascular intervention $(14,15)$.

Hydrogen sulfide $\left(\mathrm{H}_{2} \mathrm{~S}\right)$, one of the important gasotransmitters, is an endogenously produced gas signal molecule that is synthesized and catalyzed in vivo through cystathionine $\beta$-synthase and cystathionine $\gamma$-lyase, respectively (16). $\mathrm{H}_{2} \mathrm{~S}$ is involved in a number of beneficial reactions in cardiovascular tissues, thereby regulating multiple physiological functions, including anti-oxidation, angiogenesis and vasodilation (17). According to the literature, $\mathrm{H}_{2} \mathrm{~S}$ has cardioprotective effects via the inhibition of intimal hyperplasia after peripheral angioplasty $(18,19)$ and antioxidative effects through the elimination of hydrogen peroxide $\left(\mathrm{H}_{2} \mathrm{O}_{2}\right)$ and superoxide anion, thereby suppressing myocardial ischemic injury (20). Nuclear factor-E2-related factor 2 (Nrf2), a transcription factor with a high sensitivity to oxidative stress, exerts antioxidative effects by binding to antioxidant response elements (AREs) in the nucleus and regulating the expression of downstream antioxidant genes, including heme oxygenase (HO)-1 (21). A previous study demonstrated that $\mathrm{Nrf} 2$ may be involved in the antioxidative activity of $\mathrm{H}_{2} \mathrm{~S}$ in $\mathrm{H}_{2} \mathrm{~S}$-mediated cardioprotection (22). In addition, hypoxia-inducible factor (HIF-1), a protein comprising HIF- $1 \alpha$ and HIF-1 $\beta$ subunits, has been revealed to serve an important role in regulating angiogenesis, which is beneficial for wound healing during peripheral angioplasty-induced blood vessel injury (23). Thus, it may be hypothesized that the Nrf2 signaling pathway and HIF-1 $\alpha$ serve roles in the anti-restenosis effects of $\mathrm{H}_{2} \mathrm{~S}$.

Although the physiological and cardioprotective effects of $\mathrm{H}_{2} \mathrm{~S}$ have previously been documented, the anti-restenosis effect and molecular mechanisms have not been fully evaluated. Therefore, the purpose of the present study was to investigate the anti-restenosis effect and signaling mechanisms induced by $\mathrm{H}_{2} \mathrm{~S}$ donor (NaHS) treatment using an in vivo model of restenosis and in vitro cell culture.

\section{Materials and methods}

Animals. A total of 24 healthy adult male Sprague-Dawley (SD) rats $(8-9$ weeks, $250 \pm 30 \mathrm{~g})$ were purchased from the Hubei Provincial Center for Disease Control and Prevention (Hubei, China). The rats were housed under controlled conditions of $22 \pm 2^{\circ} \mathrm{C}$ and $55 \pm 5 \%$ humidity under a 12 -h light/12-h dark cycle and access to food and water ad libitum. The rats were acclimatized for at least 1 week prior to being used in the experiments. All experiments involving animal treatment were performed in accordance with the National Institutes of Health Guide for the Care and Use of Laboratory Animals, and the protocol was approved by the Ethics Committee of Union Hospital, affiliated to the Huazhong University of Science and Technology (approval no. TJ-A20161216).

Construction of the balloon dilatation restenosis model and NaHS treatment. All animals were randomly divided into three groups: Normal, model and model+NaHS groups $(n=8)$. The rats that did not receive the balloon injury (sham-operated) were used as normal controls. The rats in the model group (balloon injury) underwent balloon catheter injury to construct the balloon dilatation restenosis model as previously described $(8,24)$ and were allowed to recover for 4 weeks. In brief, the rats were anesthetized by intraperitoneal injection of $40 \mathrm{mg} / \mathrm{kg}$ pentobarbital and the right external carotid artery in the neck was isolated using a midline incision. The distal end of the right external carotid artery was ligated with a nylon suture, while the proximal part was clamped with a bulldog clamp. Then, a small opening was made in the distal end of the right external carotid artery using eye scissors. A 2F balloon catheter (Edwards Lifesciences, Irvine, CA, USA) was inserted into the right external carotid artery and inflated with $200 \mu \mathrm{l}$ saline. Next, the balloon catheter was pulled back through the external carotid artery to break the blood vessel endothelium. This manipulation was repeated thrice. Then, the balloon catheter was removed after $20 \mathrm{~min}$; the external carotid artery was ligated and the incisions to the vessel and skin were closed. Penicillin was used topically to prevent infection following the surgery. The rats in the model+NaHS group underwent the same balloon catheter injury and received treatment with $\mathrm{H}_{2} \mathrm{~S}$ in the form of sodium hydrosulfide (NaHS, a donor of $\mathrm{H}_{2} \mathrm{~S}$; Sigma-Aldrich; Merck KGaA, Darmstadt, Germany). Treatment with NaHS (30 $\mu \mathrm{mol} / \mathrm{kg}$ ) was performed by intraperitoneal injection prior to the surgery and continued for 4 consecutive weeks following the surgery, once a day.

Cell culture and treatment. Human umbilical vein endothelial cells (HUVECs) were obtained from American Type Culture Collection (Manassas, VA, USA) and cultured in M200 (Gibco; Thermo Fisher Scientific, Inc., Waltham, MA, USA) containing $10 \%$ fetal bovine serum (FBS; Hyclone; GE Healthcare Life Sciences, Logan, UT, USA). Human vascular smooth muscle cells (HVSMCs) were obtained from American Type Culture Collection and cultured in smooth muscle cell medium (ScienCell Research Laboratories, Inc., San Diego, CA, USA) containing 10\% FBS. The two cell types were maintained at $37^{\circ} \mathrm{C}$ in a humidified incubator with $5 \% \mathrm{CO}_{2}$. Once $75 \%$ cell confluence was achieved, they were treated with NaHS $(0,50$, 100 or $200 \mu \mathrm{mol} / \mathrm{l})$ for $48 \mathrm{~h}$. The effect of NaHS on HVSMC proliferation was detected using an MTT cell proliferation and cytotoxicity assay kit (Nanjing Jiancheng Bioengineering Institute, Nanjing, China). The untreated group was considered as the control group. Furthermore, $\sim 2 \times 10^{5}$ HUVECs were cultured in 6-well plates and at 70-80\% cell confluence, the cells were treated with NaHS and then transfected with small interfering (si)RNA of target sequences, including siNrf2 (5'-CAUUGAUGUUUCUGAUCUATT-3'; $100 \mathrm{nM}, 48 \mathrm{~h}$ ), siHIF-1 $\alpha$ (5'-CUGAUAACGUGAACAAAUATT-3'; $100 \mathrm{nM}$, $48 \mathrm{~h}$ ) or siRNA negative control (siNC; 5'-GGUCUCACU CCCCAUAGAGTT-3'; 100 nM, 48 h; all Guangzhou RiboBio Co., Ltd., Guangzhou, China) using the Lipofectamine RNAiMAX transfection reagent (Invitrogen; Thermo Fisher Scientific Inc., Waltham, MA, USA). Cultured cells that had not been transfected with siRNA or treated with NaHS were used as controls.

Histological observation. After 4 weeks of treatment, the rats were euthanized by overdose anesthetics $(100 \mathrm{mg} / \mathrm{kg}$ pentobarbital). Then, the right carotid arteries were isolated, placed in a cold saline solution and the surrounding adipose tissue was dislodged from the carotid artery samples. Subsequently, 
the artery samples were cut into vessel segments $(3.0 \mathrm{~mm})$ and fixed in $4 \%$ paraformaldehyde for $1 \mathrm{~h}$ at room temperature. The artery samples were embedded into paraffin blocks using conventional procedures (25), including dehydration, transparency, dipping and embedding. For morphological observation, $5.0-\mu \mathrm{m}$ thick sections were stained with hematoxylin and eosin (H\&E) staining solution $(0.2 \%$ hematoxylin solution and $1 \%$ eosin solution; Nanjing Jiancheng Bioengineering Institute) according to the manufacturer's protocol. The areas occupied by the external elastic lamina, the internal elastic lamina and the lumen areas were measured by an optical microscope at a magnification of x100. Other areas were calculated as follows: Neointimal area, internal elastic lamina area - lumen area; medial area, external elastic lamina - internal elastic lamina; and $\%$ of lumen stenosis/normal, (lumen area in normal group - lumen area in model or treatment group) / lumen area in normal group.

Measurement of endogenous $\mathrm{H}_{2} \mathrm{~S}$ production. Carotid artery tissue and plasma $\mathrm{H}_{2} \mathrm{~S}$ production was measured using the $\mathrm{H}_{2} \mathrm{~S}$ content assay kit (Beijing Solarbio Science \& Technology Co., Ltd., Beijing, China) according to the manufacturer's protocol.

Reverse transcription-quantitative polymerase chain reaction $(R T-q P C R)$. Carotid arteries were ground using liquid nitrogen $\left(-196^{\circ} \mathrm{C}\right)$. Total RNA was extracted from carotid arteries using TRIzol reagent (Invitrogen; Thermo Fisher Scientific, Inc.) and dissolved in RNA-free water. Next, cDNA was synthesized using the superscript ${ }^{\mathrm{TM}}$ II reverse transcriptase (Invitrogen; Thermo Fisher Scientific, Inc.) and diluted into the concentration of $100 \mathrm{ng} / \mu \mathrm{l}$ for RT-qPCR. The thermal cycling conditions for reverse transcription were as follows: $70^{\circ} \mathrm{C}$ for $10 \mathrm{~min}, 42^{\circ} \mathrm{C}$ for $50 \mathrm{~min}$ and $70^{\circ} \mathrm{C}$ for $15 \mathrm{~min}$. RT-qPCR was performed using the QuantiFast SYBR-Green PCR kit (Qiagen, Inc., Valencia, CA, USA). RT-qPCR was performed at $95^{\circ} \mathrm{C}$ for $10 \mathrm{~min}$, followed by 40 cycles at $95^{\circ} \mathrm{C}$ for $10 \mathrm{sec}, 60^{\circ} \mathrm{C}$ for $45 \mathrm{sec}$ and $72^{\circ} \mathrm{C}$ for $30 \mathrm{sec}$; and a last step at $72^{\circ} \mathrm{C}$ for $10 \mathrm{~min}$. The primers were purchased from Sangon Biotech Co., Ltd., (Shanghai, China). The primer sequences used in present study as follows: Nrf2 forward, 5'-ATTCAAGCCGATTAGAGG-3' and reverse, 5'-ATTGCTCCTTGGACATCA-3'; HO-1 forward, 5'-ATGTCCCAGGATTTGTC-3' and reverse, 5'-CTGCTT GTTTCGCTCT-3'; HIF-1 $\alpha$ forward, 5'-GGCTTTGTTATG GTGCTA-3' and reverse, 5'-TTGTTCTTTCCCCTTTCT-3'; vascular endothelial growth factor (VEGF) forward, 5'-AGGGCAGAATCATCACGAAGT-3' and reverse, 5'-AGG GTCTCGATTGGATGGCA-3'; GAPDH forward, 5'-CAA GTTCAACGGCACAG-3' and reverse, 5'-CCAGTAGACTCC ACGACAT-3'. The quantified results were normalized to those of GADPH using the $2-{ }^{\Delta \Delta \mathrm{Cq}}$ method (26).

Western blot analysis. Nuclear and cytoplasmic proteins of tissue samples were extracted using Nuclear and Cytoplasmic Protein Extraction kit (Beyotime Institute of Biotechnology, Shanghai, China) according to the manufacturer's protocol. The total protein samples from HUVECs treated with different concentrations of NaHS $(0,50,100$ or $200 \mu \mathrm{mol} / 1)$, or transfected with siNrf2, siHIF-1 $\alpha$ or si-NC were extracted using RIPA Lysis buffer containing a protease inhibitor cocktail (Roche Applied Science, Madison, WI, USA). The concentra- tion of protein was measured using a bicinchoninic acid protein assay kit. Subsequently, $15 \mu \mathrm{g}$ of protein/sample was subjected to $12 \%$ SDS-PAGE and separated proteins were transferred to polyvinylidene difluoride membranes. The membranes were blocked with $5 \%$ skim milk [dissolved in PBS containing $0.1 \%$ Tween-20 (PBST)] for $1 \mathrm{~h}$ at room temperature. Then, the membranes were incubated at $4^{\circ} \mathrm{C}$ overnight with the following primary antibodies: Rabbit monoclonal anti-Nrf2 (1:2,000; cat. no. ab62352); mouse monoclonal anti-HO-1 (1:1,000; cat. no. ab13248); mouse monoclonal anti-HIF-1 $\alpha$ (1:2,000; cat. no. ab16066); rabbit polyclonal anti-VEGF (1:2,000; cat. no. ab32152); rabbit polyclonal anti-Histone H3 (1:800; cat. no. ab61251); mouse monoclonal anti-GAPDH (1:2,000; cat. no. ab8245) (all from Abcam, Cambridge, UK). Following washing with PBST thrice, the membranes were incubated with the goat anti-rabbit IgG H\&L (1:2,000; cat. no. ab6702) or goat anti-mouse IgG H\&L (1:5,000; cat. no. ab6708) secondary antibodies (both from Abcam) for $1.5 \mathrm{~h}$ at room temperature. The protein band signals were detected using BeyoECL Plus [ultra-sensitive electrochemical luminescence (ECL) kit; Beyotime Institute of Biotechnology] and an automatic chemiluminescence analyzer (Tanon-5200; Tanon Science and Technology Co., Ltd., Shanghai, China). Gray values of bands were quantified using ImageJ software (version 1.42; National Institutes of Health, Bethesda, MD, USA) and normalized to GAPDH or Histone H3.

Immunofluorescence. HUVECs were divided into five groups: Control, NaHS treated, NaHS treated + siRNA-NC, siNrf2 transfected and NaHS treated $+\operatorname{siNrf} 2$. After $48 \mathrm{~h}, \sim 1 \times 10^{5}$ HUVECs cultured on slides were fixed in $4 \%$ paraformaldehyde for $10 \mathrm{~min}$ at room temperature, treated with $0.5 \%$ Triton $\mathrm{X}-100$ at $37^{\circ} \mathrm{C}$ for $15 \mathrm{~min}$ and blocked with $1 \%$ bovine serum albumin (Gibco; Thermo Fisher Scientific, Inc.) at room temperature for $1 \mathrm{~h}$. Subsequently, the cells were incubated with the mouse monoclonal anti-HIF-1 $\alpha$ (1:200; cat. no. ab16066; Abcam) and rabbit monoclonal anti-Nrf2 (1:300; cat. no. ab62352; Abcam) primary antibodies at room temperature for $1 \mathrm{~h}$. Next, the slides were incubated with the goat anti-mouse IgG H\&L (Alexa Fluor 488) (1:1,000; cat. no. ab150113; Abcam) and goat anti-rabbit IgG H\&L (Alexa Fluor 647) $(1: 1,000$; cat. no. ab150079; Abcam) fluorescein-conjugated secondary antibodies. The fluorescence signals were detected using an inverted fluorescence microscope at a magnification of $\mathrm{x} 200$.

Tube formation assay. HUVECs were divided into five groups: Control, NaHS treated, NaHS treated + siRNA-NC, NaHS treated + siHIF-1 $\alpha$ and VEGF treated. Matrigel (BD Biosciences; Becton, Dickinson and Company, San Jose, CA, USA) was diluted with FBS-free and growth factor-free M200 medium at a ratio of $1: 1$. Then, $50 \mu \mathrm{l}$ of the mixture was placed into 96 -well plates and incubated at $37^{\circ} \mathrm{C}$ for $30 \mathrm{~min}$. Subsequently, a cell suspension containing $1 \times 10^{4}$ HUVECs were added into the 96-well plates coated with Matrigel. Next, $50 \mathrm{ng} / \mathrm{ml}$ of recombinant human VEGF (Gibco; Thermo Fisher Scientific, Inc.) was added to the medium as the positive control group (the VEGF group). Following culturing for $12 \mathrm{~h}$, tube formation was observed under a light microscope at a magnification x100 and total tube area was evaluated using ImageJ software (v.1.42). 


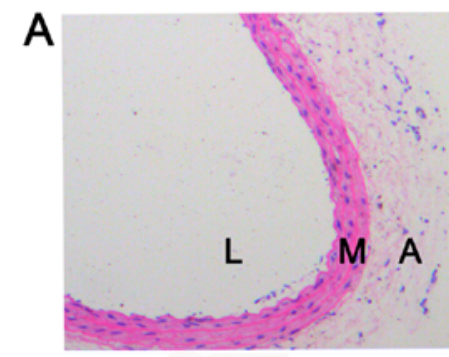

Normal

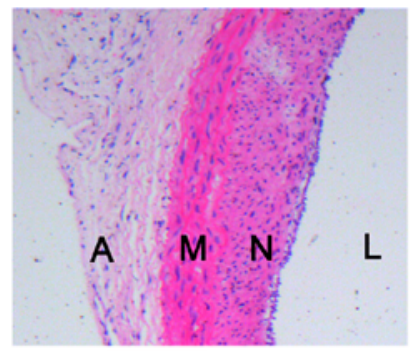

Balloon injury

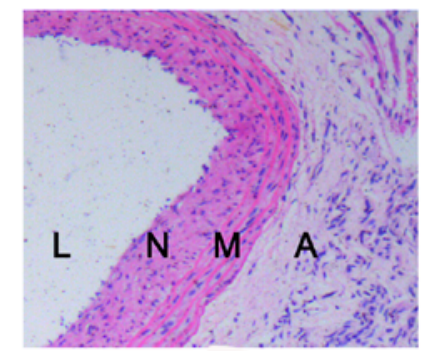

Balloon injury+NaHS
B

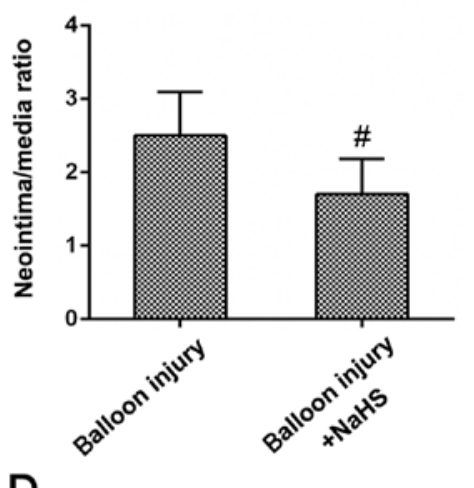

D

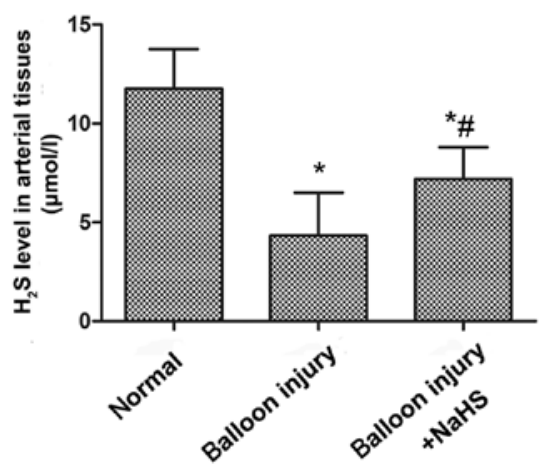

C

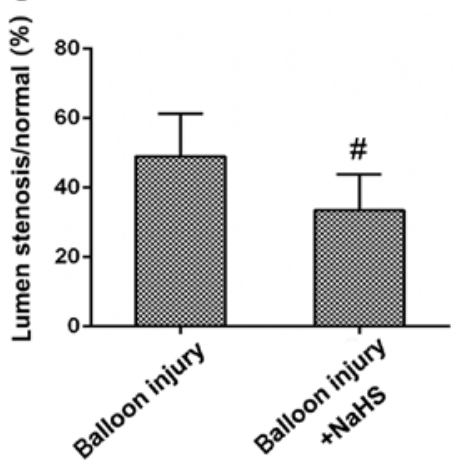

E

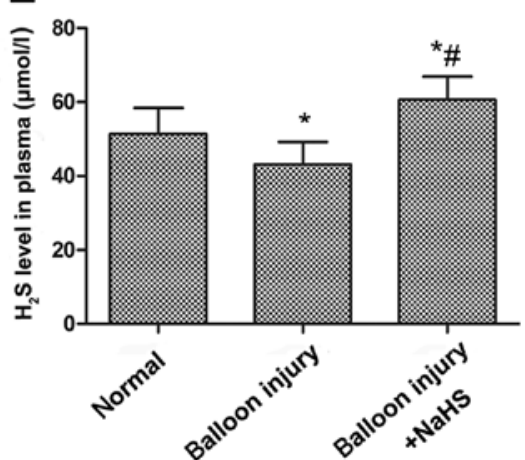

Figure 1. Effects of NaHS treatment on neointimal hyperplasia and H2S production. (A) Histological changes in the carotid artery were observed following balloon injury or NaHS treatment using haematoxylin and eosin staining (magnification, x100). Quantification of (B) neointima/media ratio and (C) \% of luminal stenosis. Increase in $\mathrm{H} 2 \mathrm{~S}$ production in (D) carotid artery tissues and (E) plasma were detected following treatment with NaHS. ${ }^{*} \mathrm{P}<0.05$ vs. the normal group; " $\mathrm{P}<0.05$ vs. the model group. A, adventitia; M, media; N, neointima; L, lumen; NaHS, sodium hydrosulfide H2S, hydrogen sulfide.

Wound scratch assay. HUVECs were divided into six groups: Control, NaHS treated, siNrf2, NaHS treated + siNrf2, siHIF-1 $\alpha$, NaHS treated + siHIF-1 $\alpha$. HVSMCs were divided into four groups: Control, $50 \mu \mathrm{mol} / 1 \mathrm{NaHS}$ treated, $100 \mu \mathrm{mol} / 1$ $\mathrm{NaHS}$ treated and $200 \mu \mathrm{mol} / 1 \mathrm{NaHS}$ treated. A cell suspension containing $2 \times 10^{5}$ HUVECs or $2 \times 10^{5}$ HVSMCs was added into 6 -well plates and cultured for $12 \mathrm{~h}$. Subsequently, the medium was replaced with fresh medium containing $2 \%$ FBS and $1 \mu \mathrm{g} / \mathrm{ml}$ mitomycin $\mathrm{C}$ to suppress cell proliferation for $12 \mathrm{~h}$. Wounds were made to the cell monolayer using $10-\mu 1$ pipette tips, and the detached cells were removed following washing with PBS heated to $37^{\circ} \mathrm{C}$. The cells were further cultured, and wound closure area was monitored for $8 \mathrm{~h}$. The migrative rate was evaluated using ImageJ software (v.1.42).

Statistical analysis. The data in the present study are expressed as the mean \pm standard deviation. Differences among multiple groups were evaluated using one-way analysis of variance followed by the Tukey's post hoc test and differences between two groups were evaluated using the Student's t-test using the statistical software SPSS v.19.0 (IBM, Corp., Armonk, $\mathrm{NY}$, USA). $\mathrm{P}<0.05$ was considered to indicate a statistically significant difference.

\section{Results}

Increased $\mathrm{H}_{2} \mathrm{~S}$ production prevents neointimal hyperplasia in $S D$ rats with carotid artery restenosis. A restenosis model was established to explore whether $\mathrm{H}_{2} \mathrm{~S}$ was able to inhibit carotid artery restenosis. As shown in Fig. 1A, neointimal hyperplasia was evident in the carotid arteries of the model group rats following balloon catheter injury. However, neointimal hyperplasia was reduced following NaHS treatment compared with the model group, as demonstrated by the significant reduction in the luminal stenosis ratio, and the ratio between the neointima and media areas (Fig. 1B and C). Measurement of $\mathrm{H}_{2} \mathrm{~S}$ production in the arterial tissues and the plasma indicated that restenosis significantly reduced $\mathrm{H}_{2} \mathrm{~S}$ expression 
A

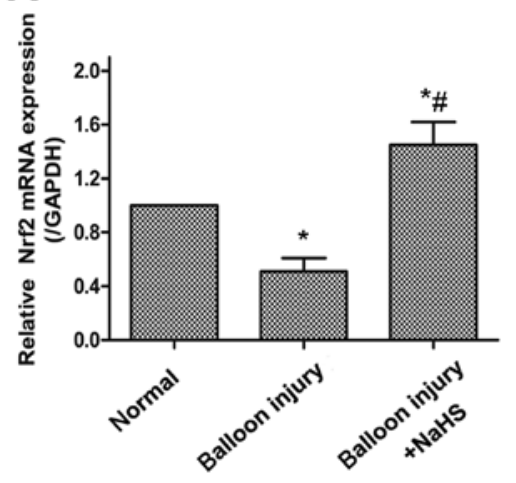

C

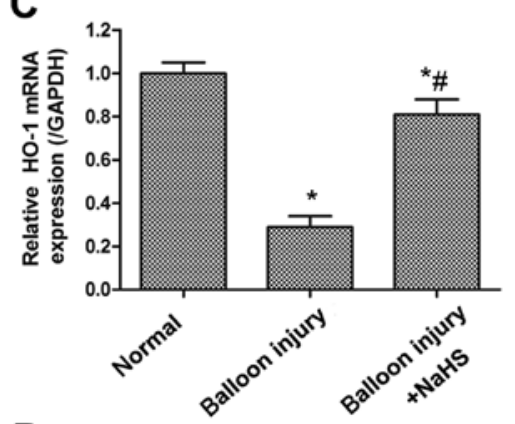

D

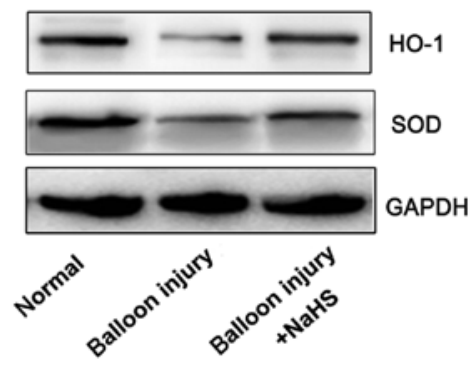

B
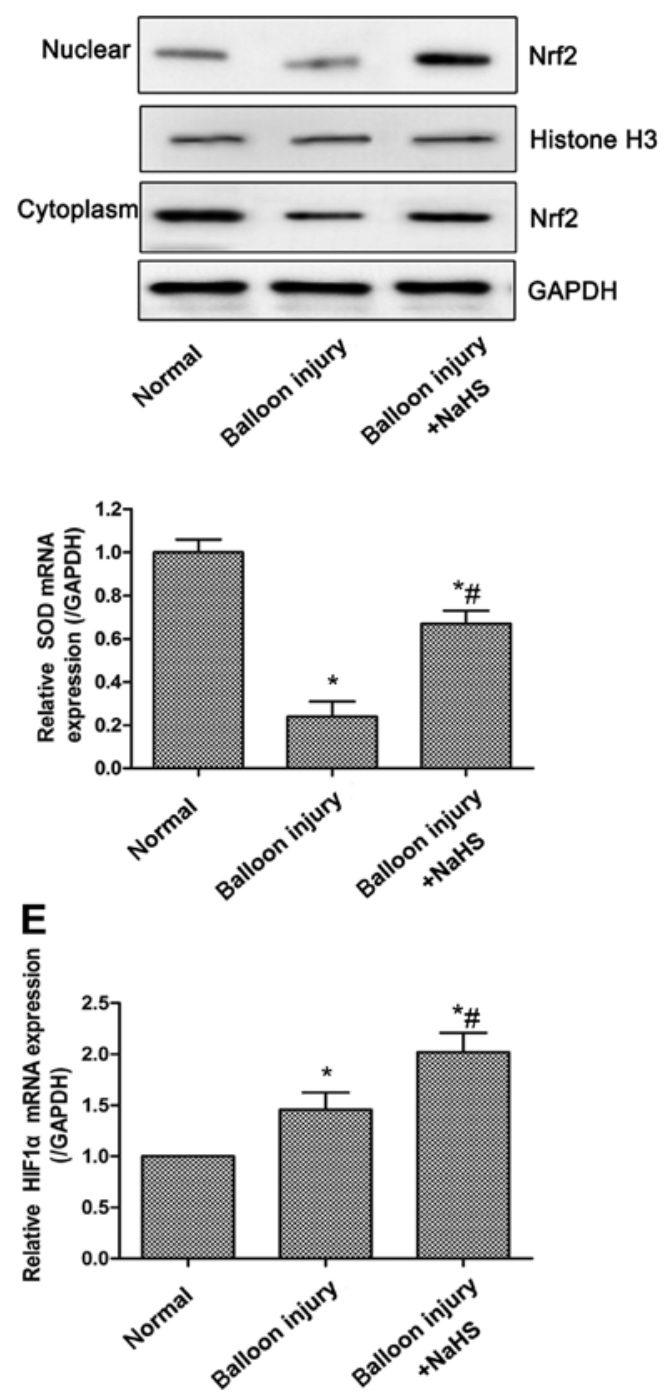

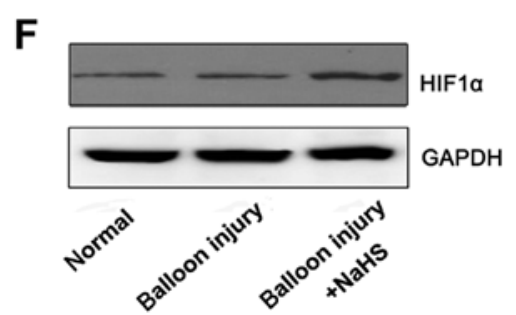

Figure 2. Effects of NaHS-induced H2S production on the expression of Nrf2/HIF-1 $\alpha$ pathway-associated proteins in carotid artery tissues. The transcriptional and protein levels of proteins were detected by RT-qPCR and western blot analysis, respectively. (A) Upregulation of Nrf2 mRNA expression in carotid artery tissues following NaHS treatment compared with model rats. (B) Nuclear and cytoplasm levels of Nrf2 protein demonstrating nuclear accumulation following treatment with NaHS. NaHS-induced increase (C) mRNA and (D) protein expression of HO-1 and SOD in carotid artery tissues. NaHS-induced increase (E) mRNA and (F) protein expression of HIF-1 $\alpha$. Representative data from three independent experiments are presented. "P<0.05 vs. the normal group; ${ }^{~} \mathrm{P}<0.05$ vs. the model group. NaHS, sodium hydrosulfide; Nrf2, nuclear factor-E2-related factor 2; HIF-1 $\alpha$, hypoxia-inducible factor-1 $\alpha$; HO-1, heme oxygenase-1; SOD, superoxide dismutase; GAPDH, glyceraldehyde-phosphate dehydrogenase.

levels compared with the sham control group (Fig. 1D and E). However, following treatment with NaHS for 4 weeks, $\mathrm{H}_{2} \mathrm{~S}$ levels in the arterial tissues and the plasma in the treatment group were significantly increased compared with the model group.

Increased $\mathrm{H}_{2} \mathrm{~S}$ production enhances antioxidative effects through Nrf2/HIF-1 $\alpha$ signaling pathway activation in vivo. Oxidative stress is associated with the progression of reste- nosis following percutaneous coronary intervention (27), and the Nrf2 signaling system has been regarded as perhaps the most important cellular defense against oxidative stress (28). Initially, the mRNA and protein expression levels of Nrf2 were examined, and it was revealed that the total mRNA expression of Nrf2 was significantly reduced in the model group compared with the sham group, whereas compared with the model group, significantly increased expression levels of Nrf2 were observed in rats treated with NaHS (Fig. 2A). Nrf2 
A

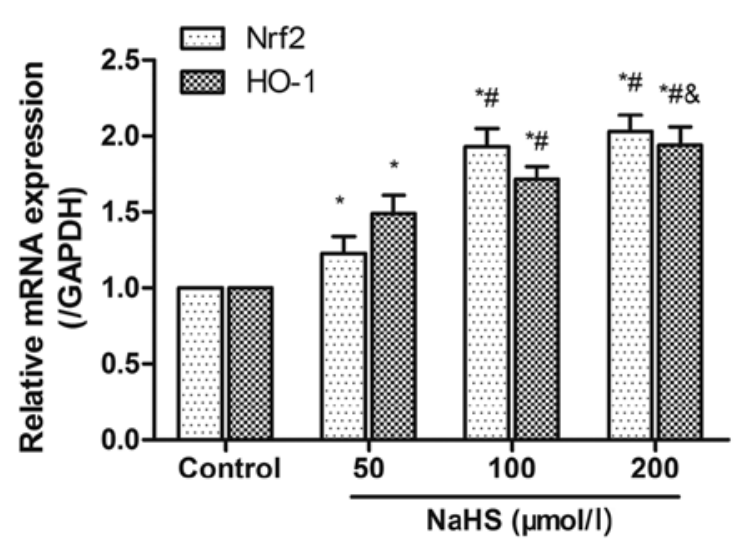

C

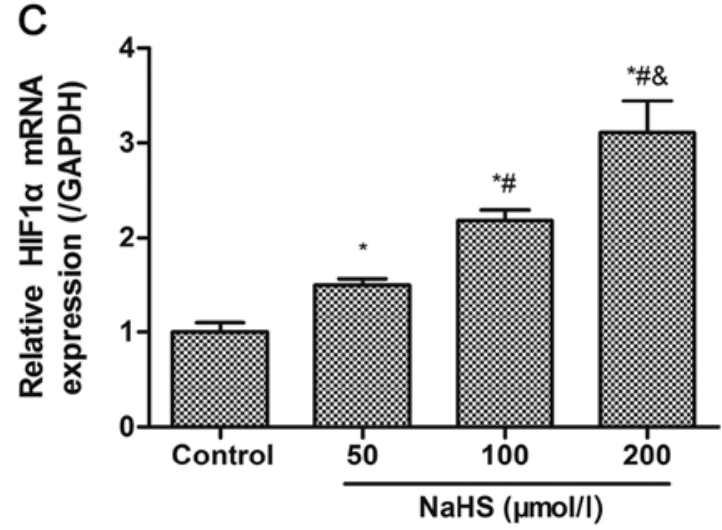

B
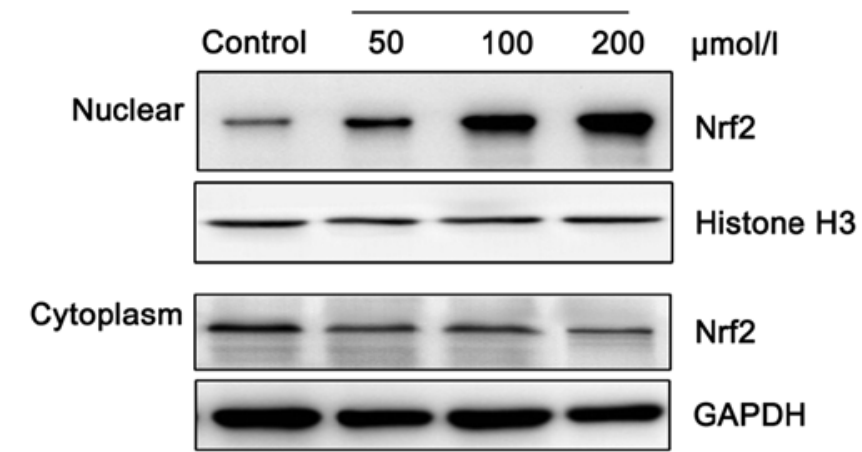

Total protein $\longrightarrow \mathrm{HO}-1$

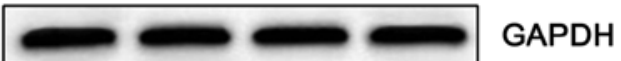

$\mathrm{D}$

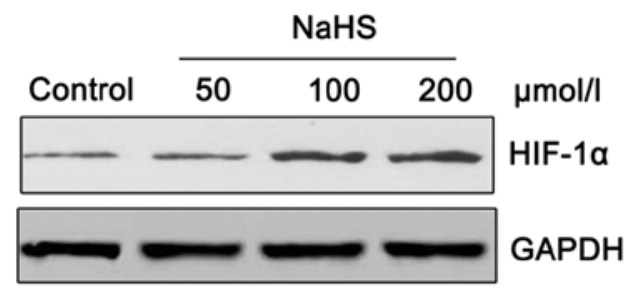

Figure 3. Effects of NaHS on the activation of the Nrf2/HIF-1 $\alpha$ signaling pathway in HUVECs. HUVECs were treated with different dosage of NaHS $(0,50$, $100,200 \mu \mathrm{mol} / \mathrm{l})$ for $48 \mathrm{~h}$. Then, the transcriptional and protein levels of Nrf2, HO-1 and HIF-1 $\alpha$ were detected by RT-qPCR and western blot analysis, respectively. (A and B) Treatment with NaHS increased (A) mRNA levels, and (B) nuclear accumulation of Nrf2 and expression of HO-1. Following treatment with NaHS, (C) mRNA and (D) protein expression levels of HIF-1 $\alpha$ increased. Representative data from three independent experiments are presented. ${ }^{*} \mathrm{P}<0.05$ vs. the control group; ${ }^{\#} \mathrm{P}<0.05$ vs. the $50 \mu \mathrm{mol} / 1 \mathrm{NaHS}$ treated group; ${ }^{\&} \mathrm{P}<0.05$ vs. the $100 \mu \mathrm{mol} / 1$ NaHS treated group. NaHS, sodium hydrosulfide; Nrf2, nuclear factor-E2-related factor 2; HIF-1 $\alpha$, hypoxia-inducible factor- $1 \alpha$; HO-1, heme oxygenase-1; GAPDH, glyceraldehyde-phosphate dehydrogenase.

expression in the nucleoprotein and plasmocin of the arterial tissues demonstrated similar changes (Fig. 2B). The expression levels of HO-1 and the antioxidative enzyme superoxide dismutase (SOD), two of the downstream genes of the Nrf2 signaling pathway, were also significantly decreased in the model group, whereas NaHS significantly upregulated HO-1 and SOD expression (Fig. 2C and D). Furthermore, HIF-1 $\alpha$ appeared to be involved in the oxidative stress response, as compared with the model group, the expression of HIF-1 $\alpha$ was significantly increased in the carotid artery tissues of rats in the model + NaHS group, whereas the expression of HIF-1 $\alpha$ was increased slightly in the model group compared with the sham group (Fig. 2E and F).

$\mathrm{H}_{2} \mathrm{~S}$ donor promotes the activation of the Nrf2/HIF-1 $\alpha$ signaling pathway in HUVECs. Oxidative stress leads to endothelial dysfunctions, which are a key factor for intimal hyperplasia (29). In order to assess the effects and its mechanisms of $\mathrm{H}_{2} \mathrm{~S}$ on oxidative stress, the expression of $\mathrm{Nrf} 2$ and HO-1 was detected in HUVECs following treatment with different dosage of NaHS $(0,50,100$ or $200 \mu \mathrm{mol} / \mathrm{l})$. As shown in Fig. 3A, the transcriptional levels of total Nrf2 and HO-1 increased in a dose-dependent manner. The nuclear protein level of Nrf2 and total protein level of HO-1 also demonstrated an increasing trend, while the cytoplasmic protein level of Nrf2 reduced with increased concentrations of NaHS (Fig. 3B). HIF-1 $\alpha$ mRNA levels significantly increased in a dose-dependent manner, which was also confirmed at the protein level (Fig. 3C and D). These data indicated that the increased $\mathrm{H}_{2} \mathrm{~S}$ production, induced by NaHS, promoted activation of the Nrf2/HIF-1 $\alpha$ signaling pathway in HUVECs. The comparison among groups demonstrated significant differences between the NaHS and control groups, whereas no significant differences were observed for Nrf2 mRNA expression and HIF-1 $\alpha$ protein expression between the 100 and $200 \mu \mathrm{mol} / 1 \mathrm{NaHS}$ groups. Thus, HUVECs was treated with $100 \mu \mathrm{mol} / 1 \mathrm{NaHS}$ in the subsequent experiments.

$\mathrm{H}_{2} \mathrm{~S}$ donor-induced HIF-1 $\alpha$ expression is dependent on the Nrf2 signaling pathway in HUVECs. In order to explore the association between HIF-1 $\alpha$ and Nrf2, Nrf2 expression was inhibited using siNrf2. As shown in Fig. 4A and B, NaHS treatment significantly increased Nrf2 mRNA expression and markedly increased Nrf2 protein expression compared with the control group. Similarly, the mRNA and protein expression levels of downstream HO-1 and HIF-1 $\alpha$ increased 

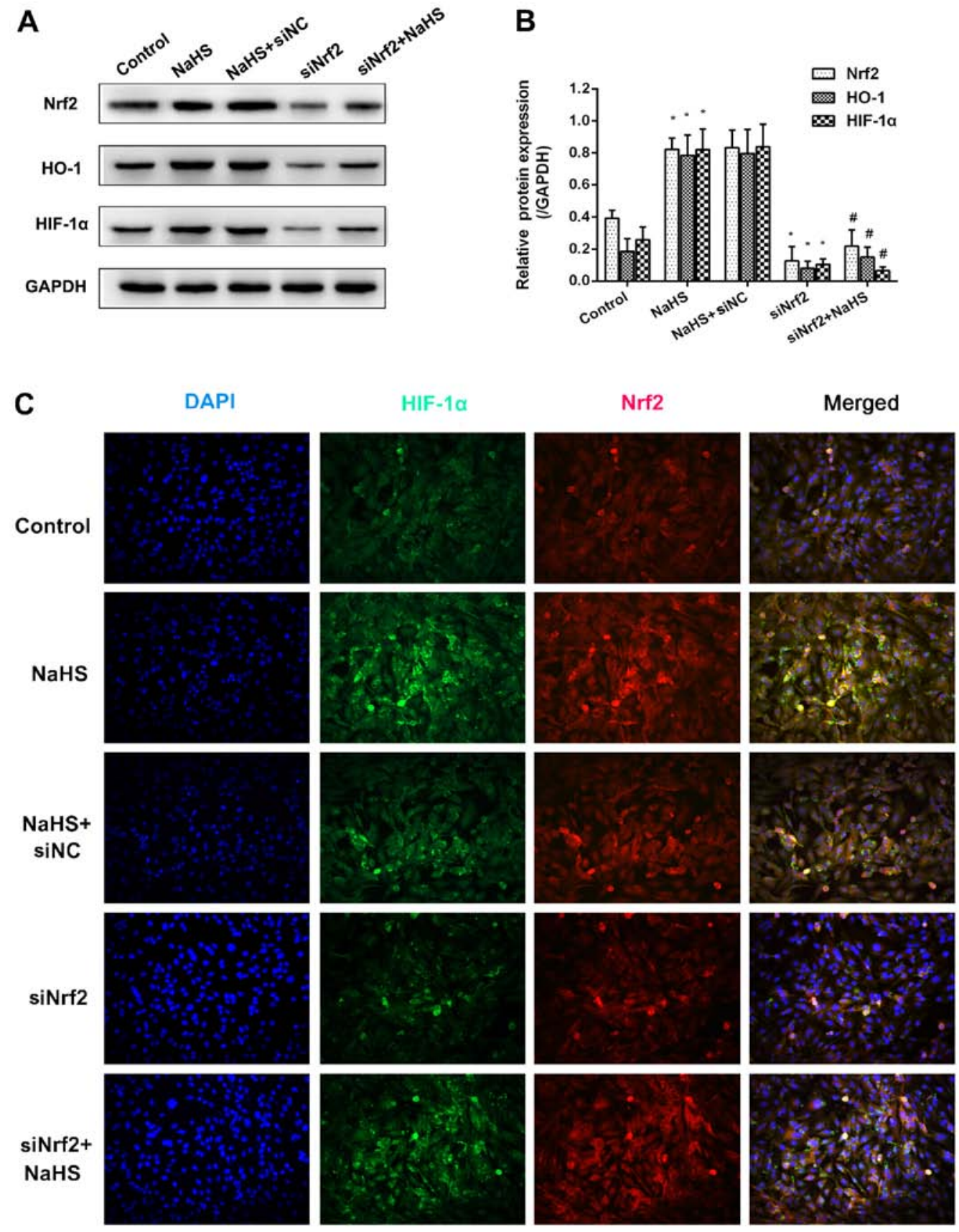

Figure 4. NaHS-induced HIF-1 $\alpha$ expression is dependent on the Nrf2 signaling pathway. (A) Representative blot and (B) quantification of Nrf2, HO-1 and HIF-1 $\alpha$ protein expression following treatment with NaHS and siNrf2. (C) The co-expression of NrF2 and HIF-1 $\alpha$ in HUVECs following treatment with NaHS and siNrf2 using immunofluorescence. Representative data from three independent experiments are presented. ${ }^{\mathrm{P}}<0.05$ vs. the control group; ${ }^{*} \mathrm{P}<0.05$ vs. the NaHS+siNC treated group. si, small interfering RNA.

following treatment with NaHS. The use of siNrf2 resulted in a significant reduction in all three mRNA levels compared with the control group. However, the effects of NaHS on the expression of HO-1 and HIF-1 $\alpha$ were not observed when Nrf2 expression was suppressed using siNrf2 when compared with the siNrf2 alone group. Furthermore, the results of immunofluorescence revealed that the fluorescence signal of Nrf2 and HIF-1 $\alpha$ evidently increased in the NaHS group, whereas the fluorescence signals of the two were markedly attenuated in the siNrf2+NaHS group compared with the NaHS group (Fig. 4C). These suggested that the $\mathrm{H}_{2} \mathrm{~S}$-induced HIF-1 $\alpha$ accumulation was dependent on the expression of Nrf2.
$\mathrm{H}_{2} \mathrm{~S}$ donor increases VEGF expression and tube formation via Nrf2/HIF-1 $\alpha$ activation in HUVECs. VEGF is a well-known pro-angiogenic factor. The mRNA and protein expressions of VEGF in HUVECs were examined by RT-qPCR and western blot analysis. As shown in Fig. 5, the mRNA and protein expression levels of VEGF were significantly increased in the NaHS group. However, inhibition of Nrf2 or HIF-1 $\alpha$ expression significantly suppressed the increased VEGF expression induced by NaHS treatment. Thus, NaHS-induced VEGF expression was dependent on the activation of the Nrf2/HIF-1 $\alpha$ signaling pathway in HUVECs. Furthermore, the tube formation assay demonstrated that compared with the control group, NaHS or VEGF treatment significantly 

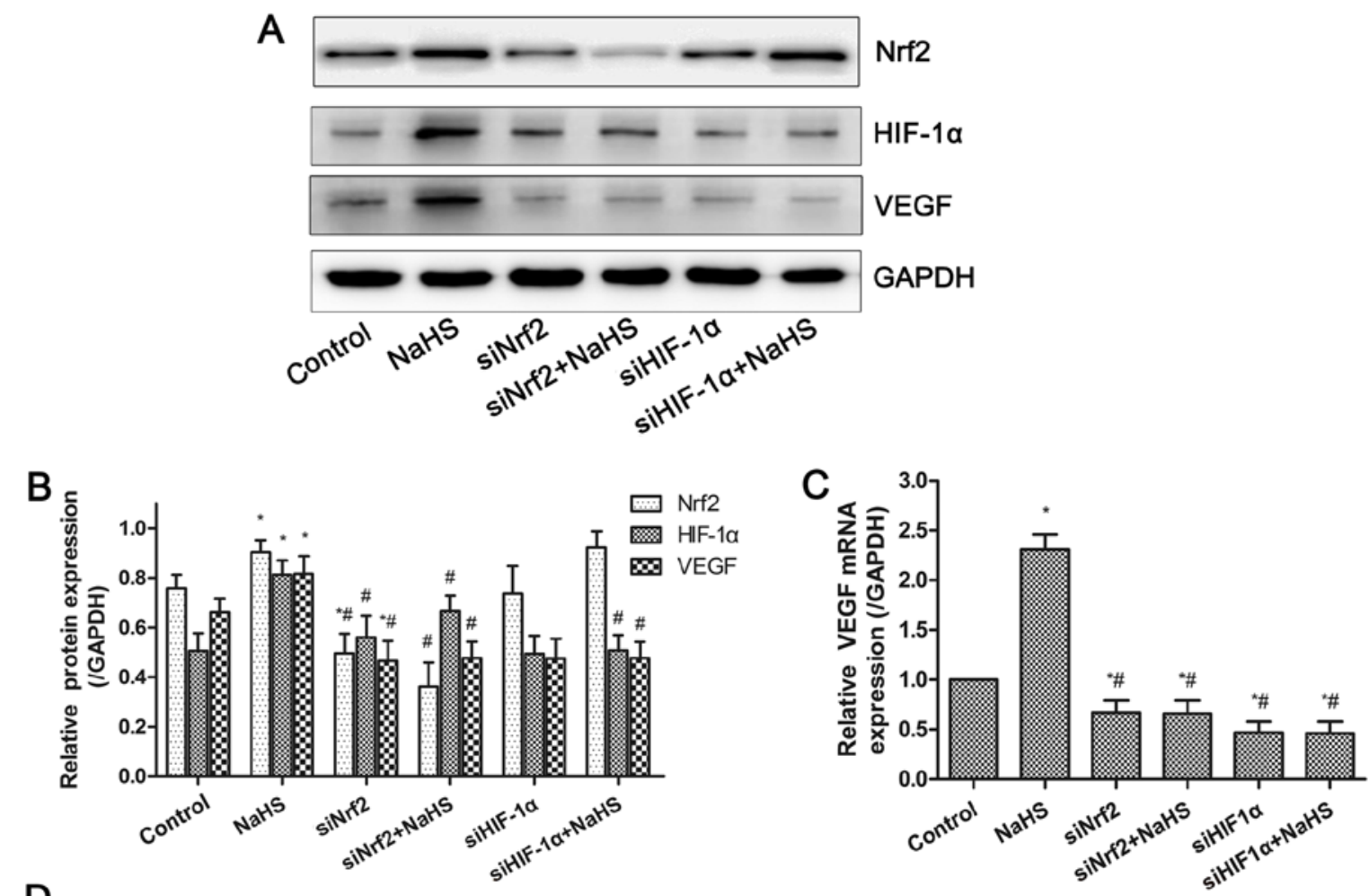

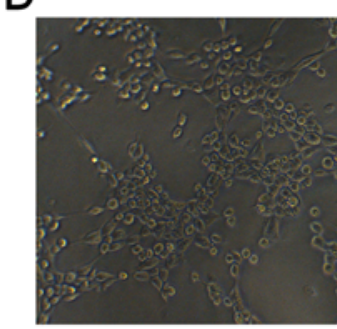

Control

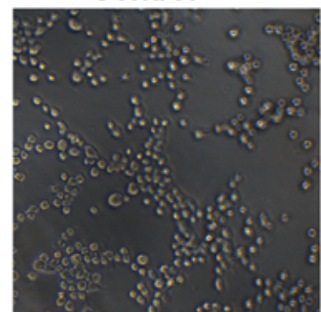

siHIF-1 $1+\mathrm{NaHS}$

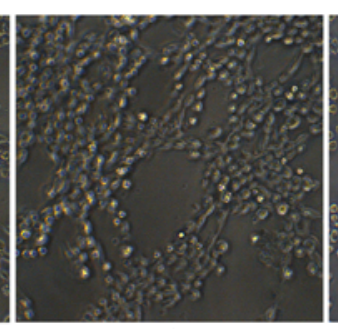

$\mathrm{NaHS}$

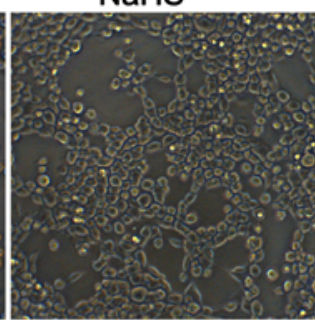

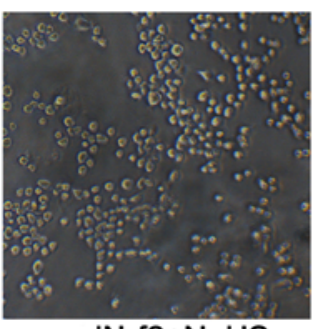

siNrf2+NaHS
E

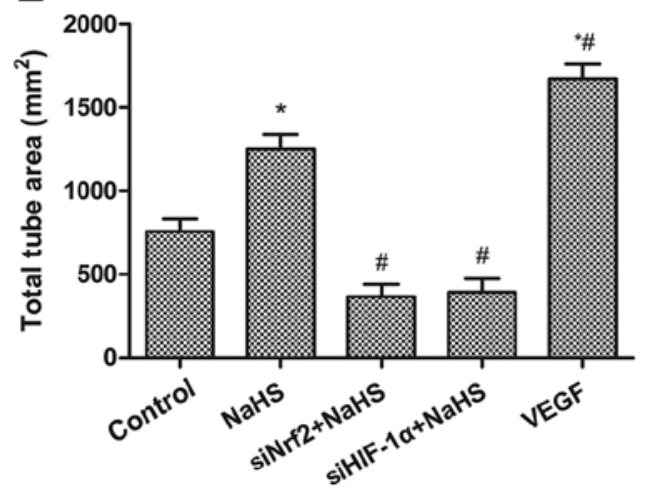

Figure 5. Effects of NaHS on VEGF expression and tube formation in HUVECs. (A) Representative blot and (B) quantification of Nrf2, HIF-1 $\alpha$ and VEGF protein expression following treatment with NaHS and siNrf2/siHIF-1 $\alpha$. (C) Decreased mRNA expression of VEGF following the treatment with NaHS and siNrf2/siHIF-1 $\alpha$, demonstrating NaHS-induced VEGF expression was dependent on the Nrf2/HIF-1 $\alpha$ signaling pathway. (D) Representative image and (E) quantification of NaHS-induced tube formation, demonstrating the inhibition of tube formation by siNrf2/siHIF-1 $\alpha$. Representative data from three independent experiments are presented. ${ }^{*} \mathrm{P}<0.05$ vs. the control group; ${ }^{\sharp} \mathrm{P}<0.05$ vs. the NaHS treated group.

promoted tube formation of HUVECs, whereas this effect was inhibited following the suppression of Nrf2 and HIF-1 $\alpha$ expression. These results indicated that NaHS treatment increased VEGF expression and tube formation via activation of Nrf2/HIF-1 $\alpha$ in HUVECs.

$\mathrm{H}_{2} \mathrm{~S}$ donor induces cell migration via Nrf2/HIF-1 $\alpha$ activation in HUVECs but inhibits HVSMC proliferation and migration. Cell migration of vascular endothelial cells to impaired region is an essential process for the repair of damaged blood vessels. The cell migratory abilities of HUVECs and HVSMCs were examined using a wound scratch migration assay. The results demonstrated that NaHS treatment accelerated cell migration of HUVECs, meanwhile cell migration ability was inhibited when Nrf2 or HIF-1 $\alpha$ expression levels were suppressed by siNrf2 and siHIF-1 $\alpha$, respectively (Fig. 6A and B). These results suggested that NaHS treatment induced cell migration by activating the Nrf2/HIF-1 $\alpha$ signaling pathway in HUVECs. For the HVSMC proliferation assay, as shown in Fig. 6C, NaHS inhibited HVSMC proliferation in a concentration-dependent manner. Similarly, this phenomenon was observed on the migratory ability of HVSMCs (Fig. 6D and E), suggesting that NaHS treatment suppressed HVSMC migration and proliferation. 
A

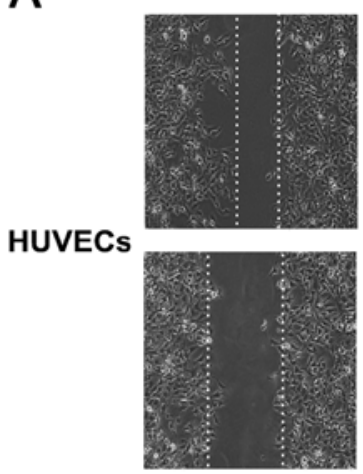

siNrf2+NaHS
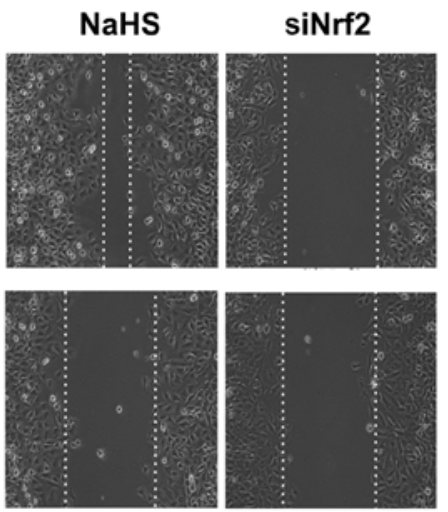

siHIF-1 $\alpha \quad$ siHIF-1 $\alpha+\mathrm{NaHS}$
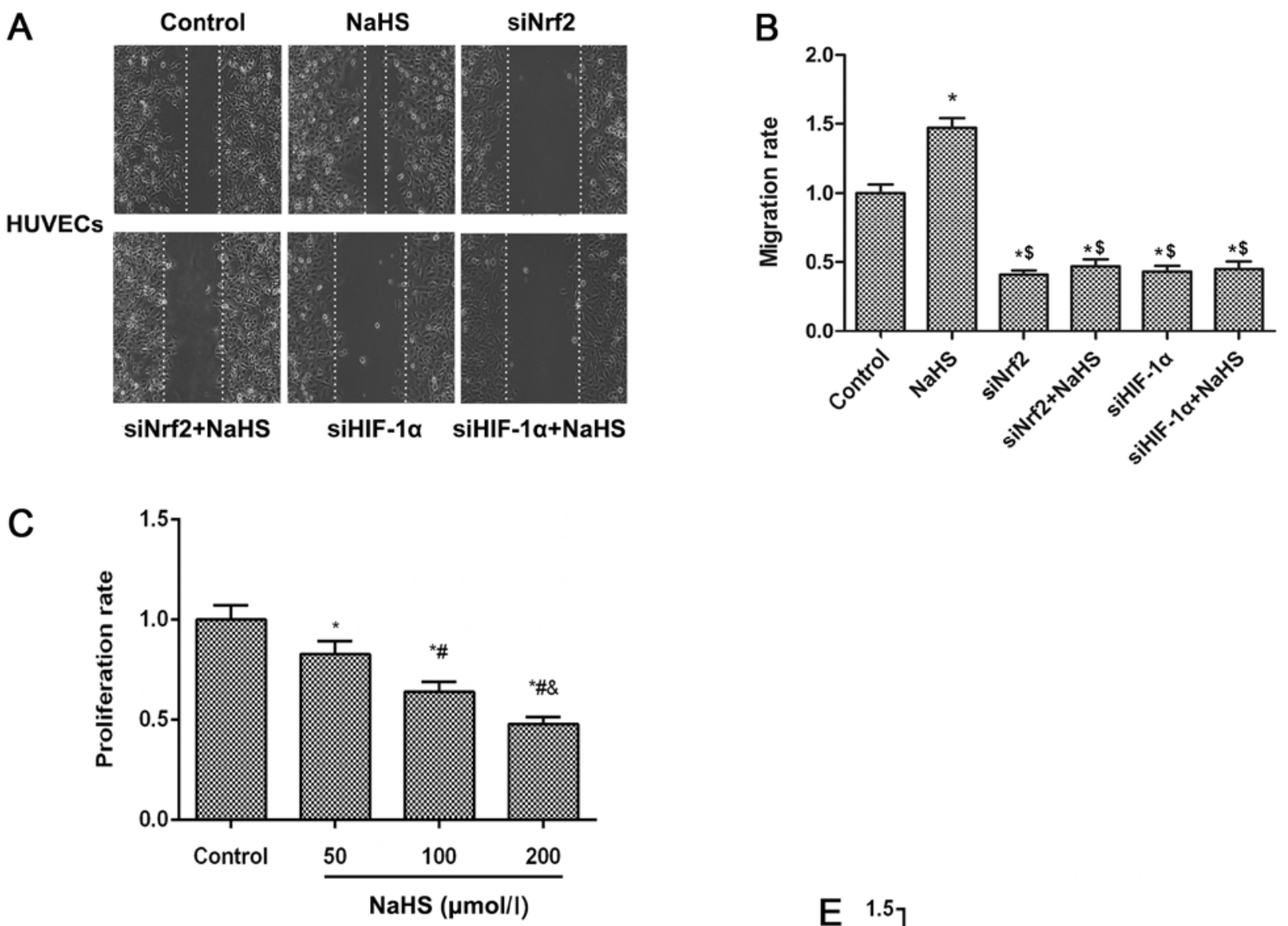

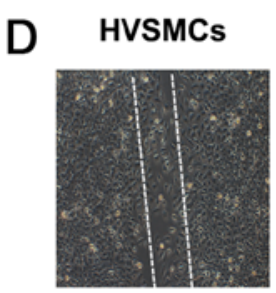

Control

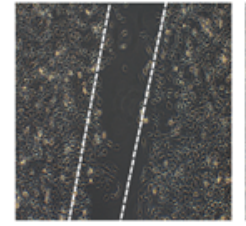

50

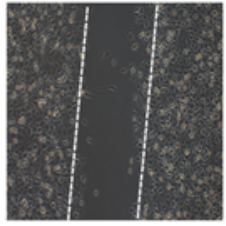

100

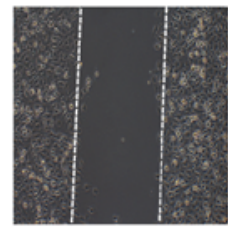

200

$\mathrm{NaHS}(\mu \mathrm{mol} / \mathrm{I})$

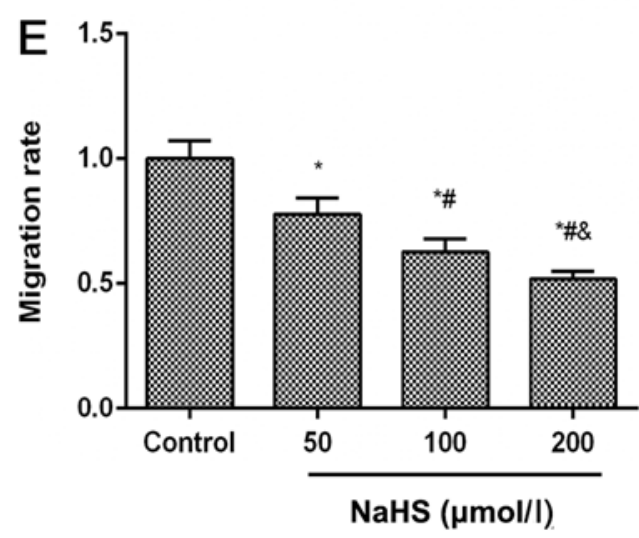

Figure 6. Effects of NaHS on cell migration and proliferation in HUVECs and HVSMCs. HUVEC migration was detected following treatment with NaHS and siNrf2/siHIF-1 $\alpha$ using a (A) wound scratch assay and the (B) migratory rate was calculated. (C) The HVSMC proliferation rates were calculated following treatment with different concentrations of NaHS using an MTT assay. (D) Representative image and (E) quantification of HVSMC migration rates as detected using a wound scratch assay. Representative data from three independent experiments are presented. ${ }^{*} \mathrm{P}<0.05$ vs. the control group; ${ }^{\$} \mathrm{P}<0.05$ vs. the NaHS treated group; ${ }^{\#} \mathrm{P}<0.05$ vs. the $50 \mu \mathrm{mol} / 1 \mathrm{NaHS}$ treated group; ${ }^{\&} \mathrm{P}<0.05$ vs. the $100 \mu \mathrm{mol} / 1 \mathrm{NaHS}$ treated group. HUEVCs, human umbilical vein endothelial cells; HVSMCs, human vascular smooth muscle cells; si, small interfering; NaHS, sodium hydrosulfide; Nrf2, nuclear factor-E2-related factor 2; HIF-1 $\alpha$, hypoxia-inducible factor- $1 \alpha$.

\section{Discussion}

It is well known that intimal hyperplasia induced by endothelial dysfunction and excessive VSMC proliferation is the central feature associated with the development of luminal stenosis diseases. During the treatment of these diseases, endovascular interventional therapies, including balloon catheter angioplasty, may induce exfoliation of endothelial cells, which triggers platelet activation and aggregation on vascular walls, leading to endothelial dysfunction (19). In response to these events, VSMCs switch to a proliferative phenotype. HVSMCs migrate through the endothelium layer and continue to grow on the inner surface of vessels, resulting in neointimal tissue formation. Accumulating evidence indicates that $\mathrm{H}_{2} \mathrm{~S}$ diminishes the progression of intimal hyperplasia and suppresses restenosis following balloon angioplasty $(20,30,31)$. In present study, a balloon injury model was used to investigate the molecular mechanisms underlying the anti-restenosis effects of $\mathrm{H}_{2} \mathrm{~S}$. Consistent with the hypothesis, the contents of $\mathrm{H}_{2} \mathrm{~S}$ in the plasma and arterial tissues were increased in the balloon injury model following NaHS (a donor of $\mathrm{H}_{2} \mathrm{~S}$ ) treatment, whereas intimal hyperplasia was suppressed. Previously, using a rabbit model with atherosclerotic-like lesions, it was demonstrated that treatment with NaHS significantly inhib- 
ited arterial restenosis by reducing the intimal area and the intima/media ratio, accompanied by reduced SMC proliferation and elevated SMC apoptosis in the neointima (32). These results are similar to those obtained in the present study, and thereby indicate that $\mathrm{H}_{2} \mathrm{~S}$ derived from exogenous NaHS is effective in treating experimentally induced vascular stenosis.

Furthermore, with respect to the pathogenesis of restenosis, increased ROS production has been observed to occur at an early stage following angioplasty (33). ROS are considered to serve a role as universal regulators in vascular biology, including in endothelial and VSMC homeostasis, the inflammatory response, vascular remodeling, and endothelial dysfunction (24). Increased ROS production may trigger increased oxidative stress, resulting in vascular damage by accelerating endothelial dysfunction and macrophage activation (33). Oxidative stress may aggravate endothelial dysfunction through a variety of pathways, including oxidation of low-density lipoproteins, upregulation of adhesion molecules and monocyte chemoattractant protein 1 chemokines, activation of matrix metalloproteinases, and inactivation of nitric oxide. In turn, these cytokines and growth factors stimulate VSMC proliferation and extracellular matrix remodeling (33). In addition to direct interaction, increased ROS or oxidative stress promotes VSMC proliferation and migration, eventually leading to the initiation and development of restenosis following PTA $(34,35)$.

Within cells, a variety of physiological antioxidant defense mechanisms haveevolved to ameliorate oxidative stress-induced damage. Activation of the Nrf2 signal pathway serves an important role in antioxidant effects through promoting the binding of AREs and upregulation of antioxidant genes. Nrf2, a well-known Cap-N-Collar transcription factor, is essential for ARE-mediated transcription, including that of NADPH quinone oxidoreductase 1 (NQO1) and HO-1 (36). Previous studies have indicated that $\mathrm{Nrf} 2$ protects against tissue fibrosis, diabetic nephropathy, and non-alcoholic fatty liver, presumably through an enhancement of cellular antioxidant capacity, such as via increased expression of NQO1 and HO-1 (37-39). In vitro experiments have indicated that the transcriptional activity and nuclear localization of Nrf2 are inhibited in various ROS-mediated cell damage models involving HUVECs and human coronary artery endothelial cells, accompanied by increases in cell apoptosis (40). Furthermore, several studies have revealed that overexpression of $\mathrm{Nrf} 2$ prevents neointimal hyperplasia by inhibiting the proliferation of VSMCs following vascular injury through HO-1-dependent antioxidant and anti-inflammatory effects $(41,42)$. The results obtained in present study indicate that the mRNA levels of Nrf2 and its nuclear accumulation are markedly decreased in rats with restenosis, and that the mRNA and protein levels of HO-1 and SOD are also reduced. Increasing evidence has indicated that activation of the Nrf2 signal pathway suppresses neointimal hyperplasia by increasing the expression of antioxidant genes, including HO-1 $(43,44)$. Other studies have demonstrated that $\mathrm{Nrf} 2$ may be involved in the antioxidant activity of $\mathrm{H}_{2} \mathrm{~S}$ during $\mathrm{H}_{2} \mathrm{~S}$-mediated cardioprotection (22). As one of the well-known target genes stimulated by Nrf2, the by-products of HO-1 have been reported to inhibit proliferation and induce apoptosis of VSMCs (45). In the present study, it was revealed NaHS treatment significantly prevented neointimal hyperplasia in rats with restenosis through increasing $\mathrm{H}_{2} \mathrm{~S}$ levels and the nuclear accumulation of Nrf2 protein. Furthermore, on the basis of its effects on HUVEC migration through increasing Nrf2 levels, NaHS treatment is also effective at inhibiting the proliferation and migration of human VSMCs. A previous in vitro experiment reported that exogenous $\mathrm{H}_{2} \mathrm{~S}$ inhibits VSMC proliferation in a hyperglycemic state via modulation of mitochondrial fusion-fission (46).

ROS production is involved in the regulation of VEGF and HIF-1 $\alpha$ expression, and angiogenesis (47). Abnormal activation of the HIF-1 $\alpha$ signaling pathway stimulates the upregulation of VEGF expression, which promotes angiogenesis (48). The results of the current study revealed that NaHS treatment increased the expression of HIF- $1 \alpha$ and VEGF, whereas inhibition of Nrf2 or HIF-1 $\alpha$ expression significantly suppressed VEGF expression, and decreased the tube formation ability of HUVECs. These results suggest that the Nrf2/HIF- $1 \alpha$ signaling pathway is involved in NaHS-induced VEGF expression. In a follicle-stimulating hormone (FSH)-induced ovarian epithelial cancer cell (OEC) model, it was previously reported that FSH induces ROS production and activation of Nrf2 signaling, whereas the elimination of ROS or knockdown of Nrf2 blocks FSH-induced VEGF expression (49). In addition, the knockdown of Nrf2 has been revealed to impair HIF-1 $\alpha$ signaling activation, indicating that ROS and the aberrant expression of Nrf2/HIF-1 $\alpha$ serve important roles in FSH-induced angiogenesis in OECs (49). The findings of a further study indicated that inhibition of Nrf2 expression restrains angiogenesis in colon cancer through suppression of the HIF-1 $\alpha$ signaling pathway (50), indicating that the HIF-1 $\alpha$ signaling pathway is regulated by Nrf2. Additionally, it has been reported that $\mathrm{H}_{2} \mathrm{~S}$ induces angiogenesis in endothelial cells and promotes damage repair (18). The proliferation and migration of endothelial cells also contribute to damage repair. The current data also indicated that NaHS treatment promoted the tube formation and migration of HUVECs in vitro, whereas the knockdown of Nrf2 or HIF-1 $\alpha$ attenuated NaHS-induced tube formation and migration in HUVECs.

In summary, the findings of the current study indicate that NaHS-derived $\mathrm{H}_{2} \mathrm{~S}$ production prevented neointimal hyperplasia in a restenosis rat model, and promoted tube formation and migration of HUVECs to accelerate damage repair. These results also demonstrate that these protective effects may be mediated via the activation of the Nrf2/HIF-1 $\alpha$ signaling pathway. Furthermore, it has been suggested that the regulation of $\mathrm{H}_{2} \mathrm{~S}$ production through the administration of $\mathrm{H}_{2} \mathrm{~S}$ donors or targeting of Nrf2/HIF-1 $\alpha$ signaling pathway may be potential strategies to prevent the development of cardiovascular narrowing diseases, including restenosis.

\section{Acknowledgements}

Not applicable.

\section{Funding}

The present study was supported by grants from the Science Foundation of Wuhan Science and Technology Bureau (grant no. 02.07.040555) and the Science Foundation of Wuhan Union Hospital (grant no. 02.03.2017-335). 


\section{Availability of data and materials}

The analyzed data sets generated during the study are available from the corresponding author on reasonable request.

\section{Authors' contributions}

KL and WW conceived of the study and drafted the manuscript together. AX designed the study and performed the statistical analysis. YC participated in the study design and constructed the balloon dilatation restenosis model. $\mathrm{XC}$ and YL performed the experiments. All authors read and approved the final manuscript.

\section{Ethics approval and consent to participate}

All experiments involving animal treatment were performed in accordance with the National Institutes of Health Guide for the Care and Use of Laboratory Animals, and the protocol was approved by the Ethics Committee of Union Hospital, affiliated to the Huazhong University of Science and Technology (approval no. TJ-A20161216).

\section{Patient consent for publication}

Not applicable.

\section{Competing interests}

The authors declare that they have no competing interests.

\section{References}

1. Holmes DR Jr, Vlietstra RE, Smith HC, Vetrovec GW, Kent KM, Cowley MJ, Faxon DP, Gruentzig AR, Kelsey SF, Detre KM, et al: Restenosis after percutaneous transluminal coronary angioplasty (PTCA): A report from the PTCA Registry of the National Heart, Lung, and Blood Institute. Am J Cardiol 53: 77C-81C, 1984.

2. Siegel RJ, Gunn J, Ahsan A, Fishbein MC, Bowes RJ, Oakley D, Wales C, Steffen W, Campbell S and Nita H: Use of therapeutic ultrasound in percutaneous coronary angioplasty. Experimental in vitro studies and initial clinical experience. Circulation 89: 1587-1592, 1994.

3. Klein AJ and Ross CB: Endovascular treatment of lower extremity peripheral arterial disease. Trends Cardiovasc Med 26: 495-512, 2016.

4. Miller AJ, Takahashi EA, Harmsen WS, Mara KC and Misra S: Treatment of Superficial Femoral Artery Restenosis. J Vasc Interv Radiol 28: 1681-1686, 2017.

5. Alazzaz A, Thornton J, Aletich VA, Debrun GM, Ausman JI and Charbel F: Intracranial percutaneous transluminal angioplasty for arteriosclerotic stenosis. Arch Neurol 57: 1625-1630, 2000.

6. Christidou FP, Kalpakidis VI, Iatrou KD, Zervidis IA, Bamichas GI, Gionanlis LC, Natse TA and Sombolos KJ: Percutaneous transluminal angioplasty (PTA) and venous stenting in hemodialysis patients with vascular access-related venous stenosis or occlusion. Radiography 12: 127-133, 2006.

7. Schmidt A, Ulrich M, Winkler B, Klaeffling C, Bausback Y, Bräunlich S, Botsios S, Kruse HJ, Varcoe RL, Kum S, et al: Angiographic patency and clinical outcome after balloon-angioplasty for extensive infrapopliteal arterial disease. Catheter Cardiovasc Interv 76: 1047-1054, 2010.

8. Meng Z, Gao P, Chen L, Peng J, Huang J, Wu M, Chen K and Zhou Z: Artificial zinc-finger transcription factor of A20 suppresses restenosis in Sprague Dawley rats after carotid injury via the PPAR $\alpha$ pathway. Mol Ther Nucleic Acids 8: 123-131, 2017.

9. Losordo DW, Isner JM and Diaz-Sandoval LJ: Endothelial recovery: The next target in restenosis prevention. Circulation 107: 2635-2637, 2003.
10. Kugiyama K, Kerns SA, Morrisett JD, Roberts R and Henry PD: Impairment of endothelium-dependent arterial relaxation by lysolecithin in modified low-density lipoproteins. Nature 344: 160-162, 1990.

11. Dussault S, Dhahri W, Desjarlais M, Mathieu R and Rivard A: Elsibucol inhibits atherosclerosis following arterial injury: Multifunctional effects on cholesterol levels, oxidative stress and inflammation. Atherosclerosis 237: 194-199, 2014.

12. Kochiadakis GE, Arfanakis DA, Marketou ME, Skalidis EI, Igoumenidis NE, Nikitovic D, Giaouzaki A, Chlouverakis G and Vardas PE: Oxidative stress changes after stent implantation: A randomized comparative study of sirolimus-eluting and bare metal stents. Int J Cardiol 142: 33-37, 2010.

13. Misra P, Reddy PC, Shukla D, Caldito GC, Yerra L and Aw TY: In-stent stenosis: Potential role of increased oxidative stress and glutathione-linked detoxification mechanisms. Angiology 59: 469-474, 2008.

14. Tardif JC, Grégoire J and L'Allier PL: Prevention of restenosis with antioxidants: Mechanisms and implications. Am J Cardiovasc Drugs 2: 323-334, 2002.

15. Strauss BH, Chisholm RJ, Keeley FW, Gotlieb AI, Logan RA and Armstrong PW: Extracellular matrix remodeling after balloon angioplasty injury in a rabbit model of restenosis. Circ Res 75: 650-658, 1994.

16. Kamoun P: Endogenous production of hydrogen sulfide in mammals. Amino Acids 26: 243-254, 2004.

17. Cheung SH and Lau JYW: Hydrogen sulfide mediates athero-protection against oxidative stress via S-sulfhydration. PLoS One 13: e0194176, 2018.

18. Altaany Z, Moccia F, Munaron L, Mancardi D and Wang R: Hydrogen sulfide and endothelial dysfunction: Relationship with nitric oxide. Curr Med Chem 21: 3646-3661, 2014.

19. Ma B, Liang G, Zhang F, Chen Y and Zhang H: Effect of hydrogen sulfide on restenosis of peripheral arteries after angioplasty. Mol Med Rep 5: 1497-1502, 2012.

20. Geng B, Chang L, Pan C, Qi Y, Zhao J, Pang Y, Du J and Tang C: Endogenous hydrogen sulfide regulation of myocardial injury induced by isoproterenol. Biochem Biophys Res Commun 318: 756-763, 2004.

21. Jian Z, Li K, Liu L, Zhang Y, Zhou Z, Li C and Gao T: Heme oxygenase-1 protects human melanocytes from $\mathrm{H} 2 \mathrm{O} 2$-induced oxidative stress via the Nrf2-ARE pathway. J Invest Dermatol 131: 1420-1427, 2011.

22. Calvert JW, Jha S, Gundewar S, Elrod JW, Ramachandran A, Pattillo CB, Kevil CG and Lefer DJ: Hydrogen sulfide mediates cardioprotection through Nrf2 signaling. Circ Res 105: 365-374, 2009.

23. Schwacha MG, Nickel E and Daniel T: Burn injury-induced alterations in wound inflammation and healing are associated with suppressed hypoxia inducible factor-1alpha expression. Mol Med 14: 628-633, 2008.

24. Patel VI,Daniel S,Longo CR,Shrikhande GV,Scali ST,CzismadiaE, Groft CM, Shukri T, Motley-Dore C, Ramsey HE, et al: A20, a modulator of smooth muscle cell proliferation and apoptosis, prevents and induces regression of neointimal hyperplasia.FASEB J 20: 1418-1430, 2006.

25. Feldman AT and Wolfe D: Tissue processing and hematoxylin and eosin staining. Methods Mol Biol 1180: 31-43, 2014.

26. Livak KJ and Schmittgen TD: Analysis of relative gene expression data using real-time quantitative PCR and the 2(-Delta Delta C(T)) Method. Methods 25: 402-408, 2001.

27. Noro T, Takehara N, Sumitomo K, Takeuchi T, Ishii Y, Kato J, Kawabe $\mathrm{J}$ and Hasebe $\mathrm{N}$ : Initial reduction of oxidative stress by angiotensin receptor blocker contributes long term outcomes after percutaneous coronary intervention. Am J Cardiovasc Dis 4: 159-167, 2014.

28. Zhang H, Davies KJA and Forman HJ: Oxidative stress response and Nrf2 signaling in aging. Free Radic Biol Med 88 (Pt B): 314-336, 2015.

29. Jiang F, Drummond GR and Dusting GJ: Suppression of oxidative stress in the endothelium and vascular wall. Endothelium 11: 79-88, 2004.

30. Jin Z, Chan H, Ning J, Lu K and Ma D: The role of hydrogen sulfide in pathologies of the vital organs and its clinical application. J Physiol Pharmacol 66: 169-179, 2015.

31. Baskar R, Sparatore A, Del Soldato P and Moore PK: Effect of S-diclofenac, a novel hydrogen sulfide releasing derivative inhibit rat vascular smooth muscle cell proliferation. Eur J Pharmacol 594: 1-8, 2008. 
32. Ma B, Liang G, Zhang F, Chen Y and Zhang H: Effect of hydrogen sulfide on restenosis of peripheral arteries after angioplasty. Mol Med Rep 5: 1497-1502, 2012

33. Chen Q, Wang Q, Zhu J, Xiao Q and Zhang L: Reactive oxygen species: Key regulators in vascular health and diseases. Br J Pharmacol 175: 1279-1292, 2018.

34. Raaz U, Toh R, Maegdefessel L, Adam M, Nakagami F, Emrich FC, Spin JM and Tsao PS: Hemodynamic regulation of reactive oxygen species: Implications for vascular diseases. Antioxid Redox Signal 20: 914-928, 2014.

35. Giacco F and Brownlee M: Oxidative stress and diabetic complications. Circ Res 107: 1058-1070, 2010.

36. Oh CJ, Kim JY, Choi YK, Kim HJ, Jeong JY, Bae KH, Park KG and Lee IK: Dimethylfumarate attenuates renal fibrosis via NF-E2-related factor 2-mediated inhibition of transforming growth factor- $\beta /$ Smad signaling. PLoS One 7: e45870, 2012.

37. Cho HY, Reddy SP, Yamamoto M and Kleeberger SR: The transcription factor NRF2 protects against pulmonary fibrosis. FASEB J 18: 1258-1260, 2004

38. Zheng H, Whitman SA, Wu W, Wondrak GT, Wong PK, Fang D and Zhang DD: Therapeutic potential of Nrf2 activators in streptozotocin-induced diabetic nephropathy. Diabetes 60: 3055-3066, 2011

39. Xu W, Shao L, Zhou C, Wang H and Guo J: Upregulation of Nrf2 expression in non-alcoholic fatty liver and steatohepatitis. Hepatogastroenterology 58: 2077-2080, 2011.

40. Chen B, Lu Y, Chen Y and Cheng J: The role of Nrf2 in oxidative stress-induced endothelial injuries. J Endocrinol 225: R83-R99, 2015.

41. Kim JY, Cho HJ, Sir JJ, Kim BK, Hur J, Youn SW, Yang HM, Jun SI, Park KW, Hwang SJ, et al: Sulfasalazine induces haem oxygenase-1 via ROS-dependent Nrf2 signalling, leading to control of neointimal hyperplasia. Cardiovasc Res 82: 550-560, 2009.

42. Lee HJ, Seo M and Lee EJ: Salvianolic acid B inhibits atherogenesis of vascular cells through induction of Nrf2-dependent heme oxygenase-1. Curr Med Chem 21: 3095-3106, 2014.

43. Ashino T, Yamamoto M, Yoshida T and Numazawa S: Redoxsensitive transcription factor Nrf2 regulates vascular smooth muscle cell migration and neointimal hyperplasia. Arterioscler Thromb Vasc Biol 33: 760-768, 2013.
44. Oh CJ, Park S, Kim JY, Kim HJ, Jeoung NH, Choi YK, Go Y, Park KG and Lee IK: Dimethylfumarate attenuates restenosis after acute vascular injury by cell-specific and Nrf2-dependent mechanisms. Redox Biol 2: 855-864, 2014.

45. Moraes JA,Barcellos-de-SouzaP,Rodrigues G,Nascimento-Silva V, Silva SV, Assreuy J, Arruda MA and Barja-Fidalgo C: Heme modulates smooth muscle cell proliferation and migration via NADPH oxidase: A counter-regulatory role for heme oxygenase system. Atherosclerosis 224: 394-400, 2012.

46. Sun A, Wang Y, Liu J, Yu X, Sun Y, Yang F, Dong S, Wu J, Zhao $\mathrm{Y}, \mathrm{Xu} \mathrm{C}$, et al: Exogenous $\mathrm{H}_{2} \mathrm{~S}$ modulates mitochondrial fusion-fission to inhibit vascular smooth muscle cell proliferation in a hyperglycemic state. Cell Biosci 6: 36, 2016.

47. Song S, Xiao X, Guo D, Mo L, Bu C, Ye W, Den Q, Liu S and Yang X: Protective effects of Paeoniflorin against AOPP-induced oxidative injury in HUVECs by blocking the ROS-HIF-1 $\alpha /$ VEGF pathway. Phytomedicine 34: 115-126, 2017.

48. Zhang Y, Liu J, Wang S, Luo X, Li Y, Lv Z, Zhu J, Lin J, Ding L and Ye Q: The DEK oncogene activates VEGF expression and promotes tumor angiogenesis and growth in HIF-1 $\alpha$-dependent and -independent manners. Oncotarget 7: 23740-23756, 2016.

49. Zhang Z, Wang Q, Ma J, Yi X, Zhu Y, Xi X, Feng Y and Jin Z: Reactive oxygen species regulate $\mathrm{FSH}$-induced expression of vascular endothelial growth factor via Nrf2 and HIF1 $\alpha$ signaling in human epithelial ovarian cancer. Oncol Rep 29: 1429-1434, 2013.

50. Kim TH, Hur EG, Kang SJ, Kim JA, Thapa D, Lee YM, Ku SK, Jung Y and Kwak MK: NRF2 blockade suppresses colon tumor angiogenesis by inhibiting hypoxia-induced activation of HIF-1 $\alpha$. Cancer Res 71: 2260-2275, 2011.

This work is licensed under a Creative Commons Attribution-NonCommercial-NoDerivatives 4.0 International (CC BY-NC-ND 4.0) License. 